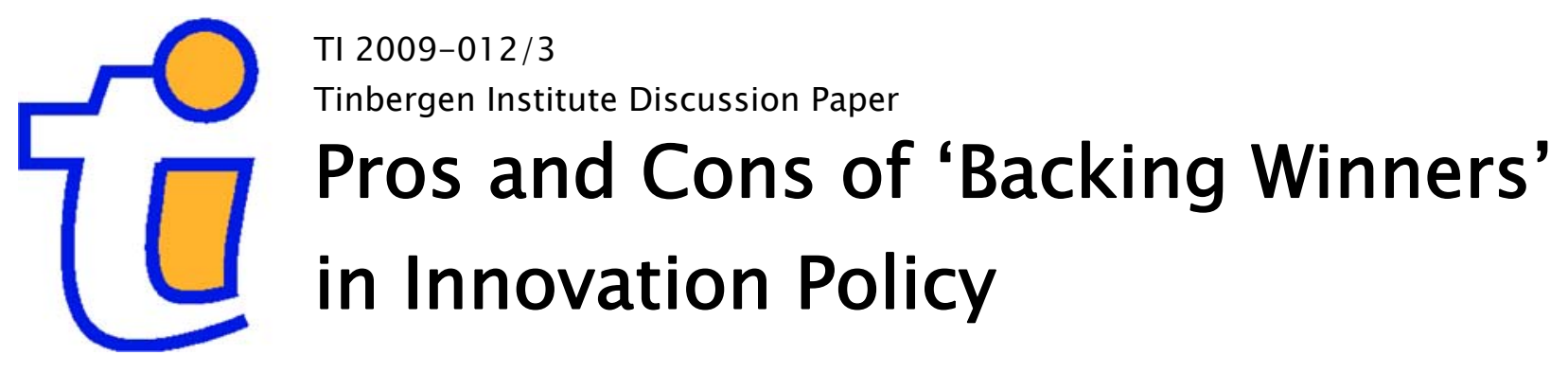

Frank A.G. den Butter*

Seung-gyu Jo

Faculty of Economics \& Business Administration, VU University Amsterdam.

" Tinbergen Institute. 


\section{Tinbergen Institute}

The Tinbergen Institute is the institute for economic research of the Erasmus Universiteit Rotterdam, Universiteit van Amsterdam, and Vrije Universiteit Amsterdam.

Tinbergen Institute Amsterdam

Roetersstraat 31

1018 WB Amsterdam

The Netherlands

Tel.: +31(0)205513500

Fax: $+31(0) 205513555$

Tinbergen Institute Rotterdam

Burg. Oudlaan 50

3062 PA Rotterdam

The Netherlands

Tel.: + $31(0) 104088900$

Fax: $+31(0) 104089031$

Most TI discussion papers can be downloaded at http://www.tinbergen.nl. 


\title{
Pros and Cons of 'Backing Winners' in Innovation Policy
}

\author{
Frank A.G. den Butter and Seung-gyu Jo ${ }^{1}$
}

\begin{abstract}
In the economics profession there is a fierce debate whether industrial and innovation policy should be targeted to specific sectors or firms. This paper discusses the welfare effects of such targeted policies from the perspective of strategic game theory of the firm. A theoretical case for picking winners through a preferential innovative policy is discussed in a third-market international trade model, which is shown to hold without evoking retaliation from foreign competitors. However, in practice information uncertainties remain a concern. The question whether in this case 'backing winners' is a wise policy option depends on the characteristics of the information asymmetries and on the extent the government is able to design selection procedures which minimize the transaction costs that may be caused from the market participants' opportunistic behavior.
\end{abstract}

Keywords: Innovation policy; R\&D subsidies, strategic trade policy, asymmetric information, spill-over effects

JEL-codes: C73, F12, O24, O32

Draft: February 2009

\footnotetext{
${ }^{1}$ Resp. professor of economics and visiting professor of economics, VU University Amsterdam.
} 


\section{CONTENTS}

1. Introduction

2. A Model for the Basic Rationale

2.1. Criticisms against the Conventional Uniform Policy

2.2. Non-uniform Innovative Policy and Aggregate Profit Creation

3. Practical Implications for Backing Winners

3.1. Robustness and Benefits of 'Backing Winners' Idea

3.1.1. Superiority of a Preferential Policy to Uniform Ones

(i) Heterogeneous Costs

(ii) Various Competition Modes

3.1.2. Implications for Backing Winners

3.1.3. Degree of Industrial Competition and Backing Potential Winners

3.2. Rationalization upon the Cost-Saving Effects of an Innovative Policy and Importance of Commitment

3.3. Mechanism Design for an Efficient Monitoring and Related Issues

3.3.1. Incomplete Information

3.3.2. An Additional Benefit of Inducing Efficiency Improving Efforts

3.3.3. Concern of Rent-Seeking Behavior and Other Transaction Costs

4. Miscellaneous Issues

4.1. R\&D Joint Venture versus Adversarial Approach

4.2. Corrective Objective versus Strategic Objective

4.3. A Political Economic Concern: Redistribution Scheme

5. Concluding Remarks 


\section{Introduction}

Both in theoretical economic analyses and in the policy arena, there is a debate about whether innovation and industrial policies favouring certain targeted industries or firms are welfare enhancing or not. For example, the "innovation platform", a think tank organised by the Dutch government with the prime minister as chairman, has selected a number of economic sectors which are believed to have a key role in the knowledge economy of the Netherlands. These sectors will have some priority in obtaining support through government funding. This policy of selecting and consequently 'backing winners' was inspired by an advice by the Advisory Council on Science and Technology (AWT, 2003). Yet much criticism was raised both against the selection procedure and the presumption that the government is able to predict which sectors or firms would be winners in innovation. For instance, Jacobs and Theeuwes (2005) asserted that it would be better to back 'challengers' instead of winners, however without indicating how the government would be able to decide about these challengers. The Scientific Council for Government Policy, in a report on innovation policy, criticized the procedure of selecting key innovative sectors by arguing that backing winners may lead to protection of existing structures, institutions and interests (WRR, 2008). The procedure excludes innovative outsiders indeed, which do not yet have the power and size to qualify as winner. Moreover it is unclear why winners need government support anyhow.

This paper discusses the options for a targeted industrial and innovation policy from the perspective of a strategic game among firms or sectors, where welfare effects of such targeted policy may stem from a cost reduction. Government support may take various forms and the conventional debate around the benefits and the scepticisms of industrial/public/trade policies will all matter one way or another. For a small open economy, in that most of the modern industries are exposed to the international competition, most of the government intervention will naturally take the international trade policy feature. While the conventional wisdom of laisser-faire is valid, in large part, under the idealized world of perfect competition, it has been identified that a strategic incentive to intervene with international trade for welfare-enhancing benefits of the policy imposing country under imperfectly competitive market structures may exist (e.g. Brander, 1985). Such shift in the theoretical stance was made from recognition of the interactive feature among the firms and governments, which is contrasted to the conventional economic reasoning based on the terms-of-trade advantage favouring restricting trade rather than promoting it (see Brander, 1995, for a good survey). The policy tools can be various, including tariffs and non-tariff instruments, export/production/R\&D subsidies and even more subtle government procurement details. The arguments received criticisms as well, which were mainly clustered upon its 'beggar-thy-neighbour' feature and the possibility of a mutually 
destructive trade war. Subsidies to specific industries or firms may lead to distortion of international competition and may lead to retaliation, in which case the policy has a negative, instead of the warranted positive effect on national welfare.

While the conventional discussions have been made around the structure of uniform - all the beneficiary firms are treated equally - policy, an asymmetric redesign of a uniformly-optimal policy may bring about a new incentive of the strategic trade policy: the industry-wise profits can be newly created without affecting the other trading partners and therefore without the usual retaliatory concern. This new feature is particularly strengthened when a public policy aims to encourage the R\&D activities by the firms. Domestic firms can be unequally treated to create an asymmetric structure of the firms' effective marginal costs. The restructured cost conditions among the firms then sets a new game rule for the firms to rationalize their output decisions, which may serve to save upon market-wise production costs for the benefit of the policy-imposing country's profit increase (Jo, 2008). This profit creation can be sustained for various technologies and thus it is distinguished from the conventional profit creating argument in the literature which is valid only when economy of scale prevails in the production technology. Also, since this new profit creation aspect of strategic R\&D subsidy remains valid without affecting the other trade-involved countries, both the other exporting competitors and the importing economy, it is robust to the usual trade war concern. It can be even shown that such strategic benefits of a non-uniform R\&D policy can enhance domestic profits even when the free trade is initially optimal. While the theoretical aspects of the new argument can be well-grounded, the practical choice of the policy details still remains questionable. For example, firms may take extra actions to be given a favour by the policy authority. It may create unhealthy transaction costs from the social welfare perspective without a visible countervailing benefit, whereas firms may take it as an incentive to economize upon their pre-policy cost conditions so that they can be picked as a winner group. The point being that the strategic feature of industrial/trade policies naturally self-contains the flip sides in terms of the firms' behaviour and its resulting welfare implications, it will be critical to sort out the important factors for the success of an industrial policy while, at the same time, staying alert for the possibilities that the undesired negative effects may be caused.

This paper aims to provide a theoretical and qualitative assessment of the pro and con side of an industrial policy so that it can give a hint under which circumstances the government innovative initiatives and targeted policies can be welfare enhancing. In the perspective of the policy discussions on whether, and if so, how to back winners - or challengers - the paper focuses on the dynamic feature an industrial policy naturally induces in the private sector through their own rationalizing behaviour. Together with the potential rationale of backing winners, the 
paper also presents the issues for which a policy authority has to be alert for a successful implementation of such a targeted policy. In this respect, our analysis sheds a meaningful light on the on-going efforts by the government to bring about efficiency gains and a welfare improvement.

The remainder of the paper is organized as follows: section 2 illustrates the above-mentioned 'aggregate-profit creation' effect of a non-uniform R\&D policy and the theoretical justification of an unequal treatment of the domestic firms, which a government may be attracted to. This strategic effect is shown to be greater as the domestic firms are treated more discriminatorily. Section 3 then discusses the practical implications. The robustness and benefits of the idea of backing winners is highlighted and the issue of how to rationalize upon the cost-saving effects of an innovative policy is also discussed. Other benefits and concerns related with the incomplete information and the proper policy design are also addressed. Section 4 touches upon the distinction between the corrective and strategic objectives of a policy and redistribution scheme matter from a political economic concern, and section 5 contains concluding remarks.

\section{A Model for the Basic Rationale}

This section presents a two-county two-sector third-market international trade model to illustrate that a country has a strategic incentive to introduce non-uniform $R \& D$ policies to create industry-wise profits without affecting the trade-related countries. This potential rationale will be used as the benchmark model to sort out the factors that may matter for a successful implementation of an innovative initiative. First, the conventional case with the initially uniform R\&D policy is reviewed so as to emphasize its beggar-thy-neighbour feature. Next the aggregate-profit creation effect of a non-uniform structure of an industrial policy is discussed. The analysis leads to the main policy guideline, that 'backing' the right targets both present and potential - should be the more important rationale than simply picking the winners when an innovative industrial policy is considered, while the latter case may still be justified under limited ideal situations.

The simplifying assumptions of the basic model are as follows. Each of the two countries, domestic and foreign, is endowed with a single factor of production, referred to as labor and denoted by $L$ and $L^{*}$ respectively using which the firms produce a numeraire good and a homogenous oligopoly good. Consumers in the two countries consume only the numeraire $\operatorname{good}^{2}$, which is produced under competitive conditions with constant returns to scale. The

\footnotetext{
${ }^{2}$ Domestic consumption of the oligopoly good and various returns to scale can be easily incorporated without affecting the main results.
} 
oligopoly sector in each country has $n(i=1,2, \ldots, n)$ and $n^{*}\left(j=1,2, \ldots, n^{*}\right)$ Cournot firms and produces under constant marginal costs only to export to the third-market. The trade is assumed to be balanced by implicitly assuming that the numeraire good is imported from the third-market in exchange for the export of the oligopoly good. The number of firms in the oligopoly sector is assumed to be fixed due to the existence of some form of entry and exit barriers. In this third-market framework, there would be no scope for an import-protective device. Rather, a government may seek to intervene with trade by promoting exports in one form or another. While this strategic aspect of an export promoting trade policy may be best presented through export subsidies, R\&D policies will be considered here since the aggregate profit-creation effect to be demonstrated in the main sections below does not occur under export subsidies ${ }^{3}$, let alone the GATT Codes limiting the practice of the latter. Initially, only the domestic government imposes an R\&D subsidy and it is assumed to be applied uniformly to all domestic firms. The case to be considered here is a two-stage game ${ }^{4}$ in which government decides upon a uniform $R \& D$ subsidy in the first stage, and the firms compete in quantities under the Cournot conjecture in the second stage possibly over more-than-one finite periods. The time structure of the game here is different from a typical one-shot game or a conventional dynamic extension of it in that the cost-reducing benefit of an R\&D policy is realized over time. The Cournot conjecture is only for demonstrational convenience and the main argument can be extended to almost all conjectural variations.

\subsection{Criticisms against the Conventional Uniform Policy}

Let $x_{i}$ and $y_{j}$ denote exports to the third oligopoly market by domestic firm $i(=1,2, . ., n)$ and foreign firm $j\left(=1,2, . ., n^{*}\right)$ which add up to the total industry output $Q . \quad c_{i}$ and $c_{j}^{*}$ denote each domestic and foreign firm's marginal cost and $\pi_{i}$ and $\pi_{j}^{*}$ denote each firm's profit from their third-market sales. Assuming the intra-country symmetric costs for the initial state, we have $c_{i}=c, c_{j}^{*}=c^{*}, x_{i}=x, y_{j}=y, Q=n x+n^{*} y, \pi_{i}=\pi$ and $\pi_{j}^{*}=\pi^{*}$ for all $i$ and $j$. Let $s$ denote the uniform R\&D subsidy to each domestic firm. Then, the after-subsidy marginal cost for a domestic firm can be defined as

$$
k=c-\alpha(S-s)-\beta s=c-((n-1) \alpha+\beta) s
$$

where $S=n s$ is the total $\mathrm{R} \& \mathrm{D}$ expenditure by the domestic government. $\beta(>0)$ represents the cost-reducing effect of the R\&D subsidy to a firm on its own marginal cost and $\alpha(>0)$ represents the external cost-reducing effect spilled over from the R\&D subsidy to all the other domestic firms. The spillover effect is assumed to work within the national border only, which

\footnotetext{
${ }^{3}$ Jo (2009) discusses differences in strategic effects of export subsidies and R\&D subsidies.

${ }^{4} \mathrm{R} \& \mathrm{D}$ process is only implicitly treated through its cost-saving effect. This is to focus on the strategic benefits of R\&D policy by avoiding unnecessary complexity that would follow an explicit treatment.
} 
can be easily extended to the case of an international spillover. Let $P(Q)$ be the inverse demand for the oligopoly good in the third market. Then the firms' profits are defined by

$$
\pi(x, y ; s)=P(Q) x-c x+((n-1) \alpha+\beta) s x ; \pi^{*}(x, y ; s)=P(Q) y-c^{*} y,
$$

and, considering that the cost-reducing benefit of the R\&D subsidy is realized over time, say $T$ periods, the relevant domestic welfare would be the following $T$-period discounted value of domestic labor income $(L)$ plus domestic firms' profit from the third-market $(n \pi)$ net of one shot government subsidy expenditures $(n s)$ with $\delta$ being the discount factor:

$$
W^{T}(s ; \delta)=\sum_{t=1}^{T} \delta^{t-1}(L+n \pi)-n s .
$$

The subgame perfect Nash equilibrium of the game is defined by the optimal subsidy $s$ satisfying the following optimization condition

$$
W_{s}^{T}(s ; \delta)=n\left(\sum_{t=1}^{T} \delta^{t-1} \pi_{s}-1\right)=0
$$

and the $T$-repetition of the one-shot Cournot-Nash equilibrium in the second stage as follows:

$$
\pi_{x}=P+x P^{\prime}-c+((n-1) \alpha+\beta) s=0 ; \quad \pi_{y}^{*}=P+y P^{\prime}-c^{*}=0,
$$

We assume that the usual regularity conditions hold globally; (i) $P^{\prime \prime}(Q)<0$ or not too much if positive $^{5}$, (ii) second order conditions for the firms $\left(\pi_{x x}=x P^{\prime \prime}+2 P^{\prime}<0, \pi_{y y}^{*}=y P^{\prime \prime}+2 P^{\prime}<0\right)$, (iii) $x$ and $y$ are strategic substitutes $\left(\pi_{x y}=x P^{\prime \prime}+P^{\prime}<0 ; \pi_{y x}^{*}=y P^{\prime \prime}+P^{\prime}<0\right)$ and (iv) the equilibrium is interior and each firm is exporting a positive amount. Then the global uniqueness of the Cournot equilibrium is implied, and a comparative statics reveals the followings: (i) $x_{s}>0, y_{s}<$ 0 , (ii) $P_{s}<0, Q_{s}>0$ and (iii) $\pi_{s}>0, \pi_{s}^{*}<0$. We can further show that the positive optimal R\&D subsidy which maximizes the national welfare $W^{T}$ exists for large $T$ and $\delta .{ }^{6}$ This unilateral incentive to offer a strategic R\&D subsidy is consistent with the conventional findings: an R\&D subsidy imposed in the first stage alters the firms' strategic interaction in the second stage of the game and thereby makes domestic firms' aggressive behavior credible in the market share rivalry, enhancing domestic national welfare even net of subsidy expenditure. This national incentive however is not confined to one country but reciprocal. It can be easily shown by considering the joint global welfare $\bar{W}^{\tau} \equiv W^{\tau}\left(s, s^{*}\right)+W^{*} \tau_{\left(s, s^{*}\right)}$, in which the $T^{*}$ period foreign welfare is

\footnotetext{
5 This is to avoid the indeterminacy of the optimal form of the policy.

${ }^{6}$ As is well known through the other literature, the signs depend jointly on the relative sizes of $n, n^{*}$ and the sign of $P^{\prime \prime}$, while the linear demand case is independent of these parameters. A large $n$, in particular, induces over-competition among the domestic firms and may lead to a negative $s$. For detailed proofs, see the appendix in Jo (2008) for the R\&D policy case and Leahy and Montana (1998) for the export subsidy case: the working mechanisms of the policies are not too different from each other.
} 


$$
\left(W^{*}\right)^{T^{*}}\left(s^{*} ; \delta^{*}\right)=\sum_{t=1}^{T *}(\delta *)^{t-1}(L *+n * \pi *)-n * s *
$$

with $\pi^{*}=P x-c^{*} y+\left((n-1) \alpha^{*}+\beta^{*}\right) s^{*} y$ and $s^{*}, \alpha^{*}, \beta^{*}, \delta^{*}, T^{*}$ defined analogously. By analogy, the foreign government's unilateral incentive for an R\&D subsidy can be implied as well, and we can readily construct further details to conclude that the mutual R\&D subsidies by both governments turns out to be jointly sub-optimal. ${ }^{7}$ The skepticism of this prisoners' dilemma phenomenon of the $R \& D$ subsidy game is reinforced and the trade war remains concern.

\subsection{Non-uniform Innovative Policy and Aggregate Profit Creation}

The conventional discussion as reviewed above assumed a uniform subsidy. When an R\&D policy takes a non-uniform structure, however, a new strategic feature can be drawn by which national policy authorities may be motivated to consider an intervention. An asymmetric treatment of the domestic firms through a non-uniform system of R\&D policy may successfully manipulate the firms' decision in the third-market and improve the national welfare without affecting other countries. Below we show the superiority of a non-uniform policy to a uniform structure when the domestic firms are homogeneous in terms of their cost structure. Later in section 3.1, we will extend it to the general case of asymmetric costs. The issue of sensitivity of the optimal policy form to the details of competition mode being one of the most effective skepticism against the conventional strategic trade policy, the robustness of the argument for various competition modes will also be discussed in section 3.1.

Suppose that the firms in each country have the same technology and thus share the same marginal costs. Assuming that the Cournot equilibrium is interior and all firms export positive quantities to the third-market, the uniform R\&D subsidies $s(\geq 0)$ and $s^{*}(\geq 0)$ will constitute an initial equilibrium. Given $s$ and $s^{*}$ from the first stage, the first order conditions for profit maximization in the second stage of the game are the same as (5):

$$
\pi_{x}=P+x P^{\prime}-c+((n-1) \alpha+\beta) s=0 ; \quad \pi_{y}^{*}=P+y P^{\prime}-c^{*}=0
$$

where $k \equiv c-((n-1) \alpha+\beta) s$ and $k^{*} \equiv c^{*}-\left(\left(n^{*}-1\right) \alpha^{*}+\beta^{*}\right) s^{*}$. Summing the first order conditions across all the firms in the oligopoly yields

$$
\left(n+n^{*}\right) P(Q)+Q P^{\prime}(Q)-\left(n k+n^{*} k^{*}\right)=0 .
$$

${ }^{7} \bar{W}_{S}^{\tau}=W_{S}^{\tau}+W_{S}^{* \tau}=W_{S}^{* \tau}=n^{*}\left(\sum_{t=1}^{\tau}\left(\delta^{*}\right)^{t-1} \pi_{S}^{*}-1\right)$ and $\bar{W}_{S^{*}}^{\tau}=W_{S^{*}}{ }^{\tau}+W_{S^{*}}^{* \tau}=W_{S^{*}}{ }^{\tau}=n\left(\sum_{t=1}^{\tau}(\delta)^{t-1} \pi_{S^{*}}-1\right)$ using

implicit function theorem and, since $\pi_{S}^{*}$ and $\pi_{S^{*}}$ are negative, it follows $\bar{W}_{S}^{\tau}<0$ and $\bar{W}_{S^{*}}^{\tau}<0$. Reducing the equilibrium subsidies improves the joint welfare. 
When the demand $P(Q)$ is non-convex or not-too-convex as assumed in the basic model, the implicit function theorem guarantees a unique $Q$. It is obvious then that the industry output $Q$, the price $P$ and therefore the industry-wide revenue $P Q$ all depend only on the sum of the marginal costs $n k+n * k *$ but not on their distribution across the firms. ${ }^{8}$ This independence implies that a rearrangement of the initially uniform subsidies into a non-uniform way preserving the total subsidy expenditure does not affect the industry output and price, while the composition of the equilibrium output of each firm changes. To prove, suppose that the domestic government redesigns the initially uniform $\mathrm{R} \& \mathrm{D}$ subsidy $\{s: n s=S\}$ to $\left\{s_{i}\right.$ : $\left.\sum_{i=1}^{n} s_{i}=n s=S\right\}$ in such a way that the variance of the subsidies increases while preserving the total R\&D subsidy expenditure $S$ and the new equilibrium still remains interior, where $s_{i}$ denotes the R\&D subsidy to domestic firm $i$ (if positive). For simplicity, the foreign subsidy is assumed to remain uniform. Then the domestic firm $i$ 's marginal cost after the redesign becomes $k_{i} \equiv\left(c-\alpha\left(S-s_{i}\right)-\beta s_{i}\right)$ whereas foreign firms' marginal cost remains the same at $k^{*}$. The first order conditions after the domestic subsidy redesign change to

$$
\pi_{x_{i}}^{i}=P(Q)+x_{i} P^{\prime}(Q)-k_{i}=0, i=1,2, \ldots, n, \quad \pi_{y}^{*}=P(Q)+y P^{\prime}(Q)-k^{*}=0 .
$$

Since $\left\{s_{i}\right\}$ is such that $\sum_{i=1}^{n} s_{i}=n s \equiv S$ and the equilibrium is interior, the sum of marginal costs $\sum_{i=1}^{n} k_{i}+\sum_{j=1}^{n^{*}} k^{*}=n c-((n-1) \alpha+\beta) S+n^{*} k^{*}$ does not change. Then we have the following observation:

Observation 1: The total industry output $Q$ and the price $P$ remain unchanged and so does the industry-wise revenue $P Q$. That is, $\Delta P=\Delta Q=\Delta(P Q)=0$.

Now we will see how domestic firms rationalize their choices when the structure of the subsidy is modified. Denoting the initial outputs of the domestic and foreign firms by $x$ and $y$, the following first order conditions need to be satisfied:

$$
\begin{gathered}
P(Q)+\left(x+\Delta x_{i}\right) P^{\prime}(Q)-\left(k+\Delta k_{i}\right)=0, i=1,2, \ldots, n, \\
P(Q)+\left(y+\Delta y_{j}\right) P^{\prime}(Q)-\left(k^{*}+\Delta k_{j} *\right)=0, j=1,2, \ldots, n^{*},
\end{gathered}
$$

where $\Delta$ denotes the changes caused by the redesign of the domestic subsidy. Since $Q$ remains the same and $\Delta k_{j}^{*}=0,(8)$ implies that the above conditions (9) and (10) are reduced to

$$
\Delta x_{i} P^{\prime}(Q)-\Delta k_{i}=0 \text { and } \Delta y_{j}=0 .
$$

\footnotetext{
${ }^{8}$ The observation that industry output and price in a Cournot industry are independent of the distribution of marginal costs has undoubtedly been noted and used several times in the literature. For example, see Bergstrom and Varian (1985), Salant and Shaffer(1999) or Bandyopadhyay et al (2004).
} 
Since $P^{\prime}<0$, it follows that $\Delta x_{i}$ and $\Delta k_{i}$ take the opposite sign from each other and the following observation is implied.

Observation 2: When the initial subsidy is redistributed in a non-uniform way as above, we observe that the output of a firm experiencing a subsidy decrease will contract and the output of a firm experiencing a subsidy increase will expand while there will be no change in the output of a firm - either domestic or foreign - whose subsidy unchanged.

Now we are ready to discuss the main feature of the arguments. $\Delta P=\Delta Q=\Delta y_{j}=0$ implies that the foreign and the third countries are not affected, allowing us to ignore the external effect of the subsidy redesign on the other involved countries and focus on the domestic welfare only. Since it also implies that the domestic firms' aggregate revenue will not change, the industrywide aggregate profits of the domestic firms will increase if and only if the domestic firms' aggregate cost of production decreases. This aggregate profit gain to the domestic firms therefore will improve the national welfare and the joint welfare of all three countries involved improves as well. In the discussions below, we explore and highlight this new feature of 'aggregate profit creation' of strategic non-uniform R\&D policies, which comes through an asymmetric treatment of the domestic firms and its aggregate cost saving effect. This cost saving effect will turn out to be greater as the subsidies are redesigned in a more discriminatory way. The intuition behind can be clearly highlighted when the initially-uniform subsidies are redesigned only across the two firms as illustrated in the Appendix. Now we consider the general case in which all the firms are treated differently from one another. From the first order conditions (8), the equilibrium output of the domestic firm $i$ is given by $x_{i}=\left(k_{i}-P\right) / P^{\prime}$ and the aggregate production cost for the domestic firms will be defined by

$$
\sum_{i=1}^{n} k_{i} x_{i}=\sum_{i=1}^{n} k_{i} \frac{k_{i}-P}{P^{\prime}}=\frac{1}{P^{\prime}} \sum_{i=1}^{n} k_{i}^{2}-\frac{P}{P^{\prime}} \sum_{i=1}^{n} k_{i}
$$

Using the variance identity for $\left\{k_{i} ; i=1,2, \ldots, n\right\}$, we can rewrite the above aggregate cost to

$$
\sum_{i=1}^{n} k_{i} x_{i}=\frac{1}{P^{\prime}}\left(n \sigma_{k}^{2}-\frac{\left(\sum_{i=1}^{n} k_{i}\right)^{2}}{n^{2}}\right)-\frac{P}{P^{\prime}} \sum_{i=1}^{n} k_{i}
$$

where $\sigma_{k}^{2}$ is the variance of $\left\{k_{i}\right\}$. Since $P^{\prime}<0$ and $\sum_{i=1}^{n} k_{i}$ remains unchanged, the aggregate cost $\sum_{i=1}^{n} k_{i} x_{i}$ decreases when the variance $\sigma_{k}^{2}$ increases. Noting $\sigma_{k}^{2}=((n-1) \alpha+\beta)^{2} \sigma_{s}^{2}$ in which $\sigma_{s}^{2}$ denotes the variance of the non-uniform domestic R\&D subsidies $\left\{s_{i}\right\}$, we can conclude that the aggregate production cost of the domestic firms becomes lower as the 
variance of the subsidies becomes greater. Domestic aggregate profit increases accordingly and thus domestic and joint world welfare improves, which effects are greater as the domestic firms are treated more discriminatorily. The following corollary summarizes the discussion.

Corollary 3: Suppose that the uniformly optimal $R \& D$ subsidy s prevailed and domestic government redesigns it in a non-uniform way so that $\sum_{i=1}^{n} s_{i}=n s=S$ and the new Nash equilibrium remains interior. Then, the domestic national welfare improves - more with a greater degree of non-uniformity of the subsidies - while the foreign and the third importing countries remain unaffected.

Note that while the foreign R\&D subsidy in the initial state may not be ruled out, the skeptical concern of a foreign retaliation, if any, is only a pre-redesign concern. Since the foreign country is not additionally affected by the domestic subsidy redesign, the aggregate profit creation effects per-se does not cause an additional foreign retaliation concern and the non-uniform R\&D subsidy system turns out to be Pareto-superior to the uniform subsidies. A country may be attracted to heavily subsidize a few firms while accommodating the loss to the firms receiving less subsidies through an appropriate national redistribution scheme. It is also noteworthy here that the incentive for an unequal treatment of the domestic firms remains valid even when free trade was initially optimal and no ex-ante R\&D policy was presumed. A detailed discussion is skipped but the necessary action will have to combine both $R \& D$ subsidies and taxes if no new public expenditure is to be financed. The R\&D expenditure and revenue can be cancelled out while the rationalizing behavior among the firms can create aggregate profits whose working mechanism is the same as the above. Or subsidizing a few (or all) firms through a newly financed fund may be considered as well if the expected welfare gain is big enough to cancel out this subsidy expenditure. Since no ex-ante efficiency difference exists and an asymmetric policy is applied in these cases, an appropriate redistribution scheme will have to be introduced to justify an arbitrary selection of those to be subsidized and those to be taxed. As an additional remark, the main argument can be extended to many directions including the case of heterogeneous costs among the firms and non-Cournot competition modes, the details of which will be discussed in the next section.

\section{Practical Implications for Backing Winners}

The reason to focus on $R \& D$ policies as a way to conduct strategic industrial policy is that it is the most relevant strategic policy tool under the current WTO regulations which prohibit a direct export or product subsidy for the developed countries. The analysis of section 2 shows that a non-uniform structure of $R \& D$ subsidies is superior to the usual uniform one as it 
enhances aggregate profit and national welfare beyond a uniform one, and does not involve a retaliation concern. Whether the unilaterally optimal R\&D policy was imposed or free trade prevailed as the initial state, it is asserted that a redesign of the initially-uniform $R \& D$ policy in a non-uniform way or a new imposition of non-uniform R\&D policy leads the firms to rationalize their behavior in a way to create industry-wise profits. Since this welfare enhancement effect is strengthened as the degree of the non-uniformity of the firm-specific policy increases, this provides a country with an incentive to further strategically stimulate private sector decisions through an asymmetric system of the R\&D policy.

The main question, however, is about the practical implementation of such non-uniform policy. The theoretical model assumes that all firms or sectors are equal and will react in the same way in case of a redistribution of $R \& D$ subsidies. More specifically equation (1) asserts that parameter $\beta$, the cost-reducing effect of the $\mathrm{R} \& \mathrm{D}$ subsidy to a firm on its own marginal cost, and parameter $\alpha$, the external cost-reducing effect spilled over from the R\&D subsidy to all the other domestic firms, take the same value for all firms or sectors. By the way, in case $\alpha>0$, we have positive spill-over externalities which may on its own be a reason for R\&D subsidies. Equation (1) also asserts that the initial marginal costs, $c$, are the same for all firms or sectors. In case $c, \alpha$ and $\beta$ are equal for each firm or sector, or when the government is unable to discriminate between firms or sectors with respect to these parameters, the policy of picking winners according to the analysis of the previous section boils down to throwing a dice to select the winners who will obtain all of the subsidies, whereas the others will lose. Obviously such policy is not feasible. First it will be legally not viable to select recipients of subsidies by a purely random selection mechanism. More importantly, however, the government may have some clue about which firms or sectors will qualify for being selected as winners. It implies that in reality the parameters $c, \alpha$ and $\beta$ will indeed differ amongst firms and sectors. In that case it seems reasonable to select those firms or sectors which have the lowest value of $c$ and the highest values of $\alpha$ and $\beta$ so that subsidizing these firms or sectors is most efficient. Then, the next questions are: how does the government find out about these different $c$ 's, $\alpha$ 's and $\beta$ 's; how do the firms or sectors react when the government is uncertain about the true values of these parameters, and how does the government assess differences between $c, \alpha$ and $\beta$ in selecting winners to be backed?

From that perspective of practical policy implementation the remainder of this section focuses on how to realize the benefits of the non-uniform policy prescription and it looks at what loopholes and caveats the policy prescription contains. The pros and cons of the discriminatory industrial policy naturally reflect the flip side of each other and a successful implementation would require one to sort out and highlight the key factors of the pro side and to pay extra 
caution to minimizing the con side. In that respect the discussion in the Netherlands on what innovation policy to conduct, with the innovation platform favoring a policy of backing winners, can act as reference case.

\subsection{Robustness and Benefits of 'Backing Winners' Idea}

This subsection builds upon the theoretical insights sketched in the previous section to provide a thinking box for an innovative policy authority on how to select winners and on how a policy authority can economize upon the benefits of such a policy. The robustness ${ }^{9}$ of the non-uniform industrial policy is illustrated first in order to highlight the superiority of a preferential innovative policy to uniform ones, when some of the assumptions of section 2 are relaxed, and then we extend our discussion to the issues that a policy authority need to pay cautions to.

\subsubsection{Superiority of a Preferential Policy to Uniform Ones}

The trade model described above emphasized the benefits of creating ex-post difference in marginal productivities through an asymmetric R\&D policy. If the initial conditions were identical, then a government can simply realize the aggregate profit creation effect by redesigning or introducing a new policy in a way that treats the firms unequally. If the firms' productivities were different initially, however, the optimal form of R\&D policy would have been asymmetric as has been well-documented in the literature (see, e.g., Neary, 1994; Leahy and Montana, 1998; Kujal and Ruiz, 2007). Also, it has been pointed out that the optimal form of the export promotion policy is sensitive to the way firms interact and the optimal policy form depends on the parameters of the economy. The basic rationale of the aggregate profit creation sketched in section 2 however can be shown to be robust to the above two concerns.

\section{(i) Heterogeneous Costs}

While the above aggregate profit creation effect can be most clearly illustrated when the firms have the same cost conditions, the heterogeneous cost case would be more practical and popular in reality. When the firms are of different efficiency in the initial state, the optimal subsidy will be naturally asymmetric from the beginning, favoring the more efficient firms. In fact, it can be shown that the more efficient firm should be given a greater subsidy, which contrasts with the conventional 'infant protection argument' which favors a policy to help those firms or industries who are lacking in competitiveness. Suppose that the firms' marginal costs

\footnotetext{
${ }^{9}$ Only the asymmetric cost case and various competition conjectures are reviewed in this report. See Jo (2008) for the robustness to the other extensions such as various returns to scale in technology and 'international' spillover of an R\&D activity etc.
} 
are asymmetric and denoted by $c_{i}$ and $c_{j}{ }^{*}$. Given the initially optimal R\&D subsidy $\left\{s_{i}\right\}$ and $\left\{s_{j}^{*}\right\}$ which would be asymmetric, let's consider a redesigned domestic - only domestic for simplicity $-\operatorname{subsidy}\left\{\tilde{s}_{i}\right\}$ for which $\sum_{i=1}^{n} \tilde{s}_{i}=n s$ does not change and the resulting new Nash equilibrium remains interior. Then the sum of the marginal costs $k_{i} \equiv c_{i}-\alpha\left(S-\tilde{s}_{i}\right)-\beta \tilde{s}_{i}$ and $k_{j}^{*} \equiv c_{j}^{*}-\alpha^{*}\left(S^{*}-s_{j}^{*}\right)-\beta^{*} s_{j}^{*}$ is preserved again after the subsidy redesign. Again Corollary 3 applies and the aggregate cost can be expressed the same as (12), assuring the aggregate profit creation effect. The intuitive proof for an illustrative case that subsidies are rearranged at two firms is provided in the Appendix. As to be mentioned below, the existing finding that the initially optimal policy is naturally asymmetric and the new finding from section 2 that an additional gain can be created by further increasing the degree of non-uniformity of the policy reinforce each other to shed a light on the main policy guideline of this paper - back the winners rather than encourage the losers.

\section{(ii) Various Competition Modes}

Although different characterizations of oligopolistic behavior would give rise to different policy suggestions (Eaton and Grossman, 1986), it can be shown that the aggregate profit creation argument as discussed above remains valid regardless of the specific form of the initial policy. It can be illustrated using the conjectural variation parameters - developed by Bowley (1924) - following the convention in the literature. A firm's conjectural variation is defined as the output response by the other firms in the industry that it conjectures would co-vary with its own output change. Formally, the conjectural variation parameters for domestic firm $i$ and foreign $j$ are defined by $v_{i}$ and $v_{j}^{*}$ such that $d Q / d x_{i}=1+v_{i}$ and $d Q / d y_{j}=1+v_{j}^{*}$. To simplify, let us assume that the firms have the symmetric conjectures: $v_{i}=v_{j}^{*}=v$ for all $i$ and $j . v<-1$ implies a pricing below marginal cost and is strictly dominated by $v=-1$ which case corresponds to a price-taking or a Bertrand game case. Since the equilibrium was assumed to be interior to guarantee positive outputs, the case of $v=-1$ can be excluded, in which case only the most efficient firm would export. Therefore we can only consider $v>-1 .{ }^{10}$ Now let's consider the domestic redesign of the initially uniform R\&D subsidy $\{s\}$ to $\left\{s_{i}\right\}$ in a nonuniform way that preserves the total subsidy expenditure, i.e. $\sum_{i=1}^{n} s_{i}=n s=S$. Then the profit maximization conditions (5) after the subsidy redesign are modified as follows:

$$
\pi_{x_{i}}^{i}=P(Q)+x_{i} P^{\prime}(Q)(1+v)-k_{i}=0 ; \pi_{y}^{*}=P(Q)+y P^{\prime}(Q)(1+v)-k^{*}=0,
$$

\footnotetext{
${ }^{10}$ As special cases, $v=0$ would correspond to the Cournot case, $\mathrm{v}>0$ represents the conjectures about more aggressive behavior than Cournot, and $v=n+n *_{-} 1$ to the collusive case. Note that there would be no aggregate profit creation effect under homogeneous product Bertrand case.
} 
where $k_{i} \equiv c-\alpha\left(S-s_{i}\right)-\beta s_{i}$ and $k^{*}=c^{*}-\left(\left(n^{*}-1\right) \alpha^{*}+\beta^{*}\right) s^{*}$. The sum of these net marginal costs $\sum_{i=1}^{n} k_{i}+\sum_{j=1}^{n^{*}} k *$ remains unchanged and the corollary 3 applies. Substituting $x_{i}=\left(k_{i}-P\right) / P^{\prime}(1+v)$ from (13) and using the variance identity for $\left\{k_{i}\right\}$, the domestic aggregate cost is expressed as follows:

$$
\sum_{i=1}^{n} k_{i} x_{i}=\frac{1}{P^{\prime}(1+v)}\left(n \sigma_{k}^{2}-\frac{\left(\sum_{i=1}^{n} k_{i}\right)^{2}}{n^{2}}\right)-\frac{P}{P^{\prime}(1+v)} \sum_{i=1}^{n} k_{i}
$$

Since $P^{\prime}>0$ and $v>-1$, the above aggregate cost decreases when the variance $\sigma_{k}^{2}$ increases and the aggregate profit creation effect is assured for a wide range of conjectural variations parameters. In the special case of $v=-1$, the resulting equilibrium will involve corner solutions and only the most efficient firm is subsidized. In all the other cases in which the equilibrium remains interior, the aggregate profit creation effect holds true when extended to general conjectural variations.

\subsubsection{Implications for Backing Winners}

The unilaterally optimal subsidy in the conventional sense brings national benefits at the expense of trading rivals and thus the retaliation possibility seriously limits the practical applicability. A unilateral deletion of an on-going subsidy does not serve a national incentive. And a mutual reduction or deletion sounds ideal but is not self-enforcing due to its prisoners' dilemma property or, even if agreeable, the operational or transaction cost - both visible and invisible - for it may amount to a non-negligible level. As such, a trade-intervention, once made, has a tendency of lasting for long. One way or another, an on-going policy can be justified and then the theoretical model shows that a non-uniform form outperforms a uniform structure. If the trade policy authority failed to realize it and the current subsidy were non-discriminatory, then the discussion of the previous section applies and the profit creation can be sought for. However, even if the actual imposition of the subsidies fully internalized the favorable market fundamentals behind and took an asymmetric structure, it is worthwhile to emphasize that such preferential subsidies outperforms the uniform subsidies in welfare improvement. A fairness argument for uniform subsidies might be raised but it should not necessarily be favored. ${ }^{11}$ Rather, a subsidy redesign had better be made in a way that helps those firms which are already cost-competitive. That is, backing the winners has to be the more relevant slogan an innovative policy authority should stick to rather than protecting the laggards. Such policy of 'helping loosers' has, by the way, been abolished by the Dutch government after a parliamentary enquiry

${ }^{11}$ Section 4 discusses whether a redistribution scheme would be required or not. 
in 1983/84 which revealed the failure of such industrial policy in the late 1960's (so called RSV-enquiry). In addition to the aggregate profit creation incentive, the idea of backing winners is further strengthened when the policy implementation process involves a mechanism through which the firms put extra efforts to improve upon their initial productivity to be eligible for beneficial policies. This may have been the intention of the Dutch innovation platform when it organized a beauty-contest-like process in order to select the winners to be backed, and be named as key innovative sectors. This point is discussed in a greater detail in later subsections.

\subsubsection{Degree of Industrial Competition and Backing Potential Winners}

As a caveat of the basic model in section 2, the argument of the model does not limit the degree of asymmetry in the way the firms are treated. In an extreme case the policy may try and create a national champion so that some firms have to exit as the degree of unequal treatment increases further. The market may become more concentrated and the ex-ante conditions for aggregate profit creation may be distorted. Not only the initially assumed uniform policy may be ungrounded but the strengthened market power of the exporting firms may also bring a detrimental effect to the trading partners, particularly the importing country, which may induce the other countries to impose a countervailing policy. It is also true that optimal form of the initial policy even before the preferential rearrangement of it may be sensitive to the relative size of the domestic and foreign firms. Too many domestic firms may induce over-competition among the domestic firms, jeopardizing the potential welfare benefits from a subsidy, and too few firms may case an anti-competitive market distortions. As such, the policy authority should make sure that the players in the market remain active and the potential newcomers should be allowed to freely enter if they find it profitable. The right degree of competition in the industry should be maintained and in this regard lifting entry and exit barriers is important. The dynamic benefits of the preferential innovative policy as contrasted to a uniform structure therefore hinge upon the idea of backing potential winners as well as the existing winners. In other words, the policy should be keen on also 'backing challengers', as advocated by Jacobs and Theeuwes (2005).

\subsection{Rationalization upon the Cost-Saving Effects $(\alpha, \beta)$ of an Innovative Policy and Importance of Commitment}

The basic rationale in section 2 relies on the following three key features: the ability of a policy authority to commit to a policy, the effectiveness of R\&D in reducing own costs, and the extent of spill-over effects. First, the commitment by government toward a particular policy constitutes an important part in the multi-stage economic models in which firms' strategic 
behavior follows the previous decision by the policy authority. As has been well indicated in game theory literature, a non-credible promise or threat does not constrain the behavior of the other players. This is why coordination or an aggressive behavior in private level often lacks in sustaining tendency even if it were agreed or tried. Unless such idea stays in its best interest, the firm would not behave as it initially declared or promised. This means that the rationalization effect to create the aggregate profits in section 2 will be realized only with the government's ability to commit to a set of industrial policy, only after which the domestic firms will adjust their behavior from their own rationalization incentive.

In the introduction of section 3 we argued that the assumption of the basic model in section 2 that the cost-reducing effects are symmetric across the firms in an industry or across the industries, is not realistic in practice. The case of heterogeneous costs discussed earlier already shows how the policy of backing winners can be designed when the initial marginal costs parameter $c$ in equation (1) vary across firms or sectors. In reality, however, the spill-over costimproving effect $(\alpha)$ and the own cost-reducing effect $(\beta)$ of an $R \& D$ policy would also vary depending on to whom the subsidy is given. An asymmetric structure of $\alpha$ and $\beta$ would be a norm rather than an exception, which case can be illustrated by the following marginal cost to firm $i$ after the R\&D policy:

$$
k_{i}=c_{i}-\sum_{j \neq i} \alpha_{i j} s_{j}-\beta_{i} s_{i}
$$

A higher $\alpha_{i j}$ means a higher spillover effect and a higher $\beta_{i}$ implies that a subsidy also improves the subsidy- recipient's cost in a greater degree. And in the aggregate production cost (12), it becomes obvious that the policy authority can further realize the welfare-enhancing effect by distributing the subsidies in a way that the firms with a higher $\beta$ receive higher subsidies and those with lower $\beta$ receive lower subsidies. By the same token, the firms that create a higher spill-over effect in terms of improving other firms' efficiency are to be preferentially treated. The latter also implies that an industry which overall shows a higher spill-over is to be given a priority as well if selecting industries were the issue. The ideal selection of the beneficiary to be backed by the innovative policies therefore could begin by looking at the size of $\alpha$ and $\beta$ for the firms across the industries to select the right industries first and then apply a non-uniform structure of subsidies to the firms in those industries.

\subsection{Mechanism Design for an Efficient Monitoring}

The criteria to back the right winners are rather straightforward as summarized above. The more challenging issue is developing an information-gathering mechanism to sort out the firms based on their productivities, self-cost-saving effects and spill-over effects. The government 
needs to utilize the existing data to derive detailed intuitions about the productivities for the firms in an industry before and after R\&D subsidies were imposed. And for a sustainable effect of welfare improvement, it is important to design and operate the mechanism through which the preferential selection of the firms be made in an efficient way. While it is natural that the policy authority does not have complete information about the private sector's parameters, a welldesigned mechanism may bring about an additional benefit to the economy by inducing the firms to take extra efforts to improve upon their pre-policy efficiency to be eligible for the subsidy rewards. On the other hand, the risk of rent-seeking behavior is present when the government's discriminatory policy is designed upon the observed performances of the firms. Therefore a successful implementation of the policy has to be of such a form in which all the agents get to internalize the costs and benefits within their own behavioral incentive system. Below we non-technically address such issues related with the informational details and the behavioral incentives of the firms. Transaction cost issues arising from the opportunistic behavior concern are also discussed.

\subsubsection{Incomplete Information}

One of the major skepticisms against an interventionism is that it presumes a good information of industry details - cost, demand, the mode of competition etc. - on the part of policy maker. Policy authority, however, is only limitedly informed. The first natural observation is that firms would behave opportunistically in order to influence their entitlement to policy benefits. Overinvestment can be the consequence. This concern was absent in the model in section 2 by assuming out private level investment or by assuming private investment was optimal. Under an incomplete information situation, a government may invent a policy menu combining a reward and a penalty through which the firms get to reveal their true types so that the government can reflect on the actions taken by the firms to come up with the appropriate form of discriminatory policy (separating equilibrium). In that the uniform policy would be the alternative if the screening effort fails and the ex-ante private information were not revealed (pooling equilibrium), well-designed mechanism would be inevitable for a successful realization of the best welfare outcome. On the contrary, a separating equilibrium in which different types of firms take different actions enabling the government to treat them discriminatorily is not always a better option than a pooling equilibrium in which all the firms take the same actions and are treated in a uniform way. In this regards, a policy maker should pay extra attention to the details of the incomplete information when designing an innovative policy. 


\subsubsection{An Additional Benefit of Inducing Efficiency Improving Efforts}

When the innovative policy is to be imposed in a discriminatory way based on the pre-policy efficiency level of the firms, the firms would take it as an incentive scheme and would try to enhance their productivity even before the subsidy assignment to the firms. A virtuous cycle of high productivity-high subsidy-high productivity will further separate the good firms from the bad firms, and the preferential subsidy mechanism can set a binding platform for this selfselecting process. This additional efficiency-gaining effect is distinguished from the usual screening mechanism which is often useful under an asymmetric information situation. The latter solely aims to separate the good firms from the bad firms while the proposed R\&D policy implementation mechanism would drive even the less efficient firms to put in their efforts not to further stay behind. That is, not only the separating equilibrium but also the pooling equilibrium may bring a welfare gain from the national perspective. To compensate those firms who improved in efficiency yet ended up receiving lower subsidies due to its lower-thanaverage productivity improvement, the government may introduce an additional subsidy if available.

\subsubsection{Concern of Rent-Seeking Behavior and Other Transaction Costs}

However, when selecting the right firms is the central focus of the mechanism, the firms' efforts to receive a high subsidy may lead the firms to behave to the selection mechanism only. The so-called rent-seeking behavior may prevail before the actual subsidy assignment. This rent-seeking incentive typically leads to the prisoners' dilemma situation, in which all firms tend to take an action only to be picked for a higher subsidy but with no practical contribution toward the meaningful efficiency improvement, yielding the socially undesirable outcome. This phenomenon can be clearly captured by designing a game in which the order of movements between the firms and government is reversed (see e.g. Gruenspecht, 1988). If the government assigns subsidies after firms take an action to signal their types in terms of their productivities, all the firms would have an incentive to over-invest for a lower cost to be eligible for a more beneficial subsidy. The subsidy assignment mechanism can help to mitigate such an incentive if the mechanism contains the self-adjusting system in which those who received a higher subsidy yet did not show a meaningful performance in productivity gain expost should be further penalized through a lower subsidy. The plausibility of an effective incentive mechanism for the genuine cost-reducing efforts prior to the subsidy assignment can be seen through the framework of the repeated games in game theory. Firms would select to play opportunistically when the game is played only once or just a few finite times. But when the firms are conscious of the through monitoring mechanism in which the policy authority regularly updates the details, they will necessarily weigh the potential gains and losses from 
such an opportunistic behavior. In this regard, a deliberately designed follow-up program of the industrial policy is needed to manipulate the subsidy recipients to behave toward the socially desirable outcome. The productivity gaining efforts by a firm to be eligible for a higher subsidy could be exercised through a visible investment in new technology or penetrating into a new market for a higher scale economy realization. Or firms might seek an efficiency gain through non-tangible resources which had been available yet not utilized. All kinds like operational, technical and managerial resources might have not been optimally exercised and the R\&D policy mechanism would give the firms to reach their optimal utilization for all possible business areas. These all contribute toward reducing the transaction costs, which need to be all counted as the positive feature of the mechanism. The transaction costs can be saved on the policy authority side as well throughout the whole channels of sorting out the recipients assigning subsidies - and monitoring the outcome for the next rounds of subsidy imposition.

\section{Miscellaneous Issues}

\subsection{R\&D Joint Venture versus Adversarial Approach}

As another meaningful intuition, the relative size of $\alpha$ and $\beta$ in (15) can shed a light on the debate about which policy between R\&D joint venture - i.e. cooperation among the firms - and adversarial approach is to be adopted. Particularly, related with the possibility of the rentseeking behavior by the firms as an opportunistic behavior, it is worthwhile to make comments on the issue of whether a cooperative $R \& D$ joint venture should be preferred or the conventional adversarial approach should be favored (see e.g., Neary and O'Sullvan, 1999). One concern about the adversarial approach is that it provides a firm an incentive to over-invest or under-invest. The former case matters if the spill-over effect is negligible and thus a firm has an incentive to more-than-optimally invest to give itself a strategic advantage against its rivals in subsequent product-market competition. And the latter case becomes real if the spillover effect is substantial and thus a firm faces an incentive to less-than-optimally invest lest its rivals enjoy the benefits of its investments. The basic model in section 2 assumed out this issue of a suboptimal level of private investment by implicitly treating the private activity stage only through the cost-reducing effects of the investment. However, the issue remains a concern and encouraging an $R \& D$ joint venture as an alternative to the above-addressed adversarial approach could be an option. Given the two-faced potential sub-optimality of an outcome when non-adversarial approach was adopted, we can at least suggest a rule-of-thumb criterion on the matter: when the spill-over effects $\left(\alpha_{i j}\right)$ dominate the own-cost reducing effect $\left(\beta_{i}\right)$, an R\&D joint venture had better be encouraged through which the cost-reducing effect of an $R \& D$ policy will be maximized although the aggregate profit creation may not be obtainable. Otherwise, an adversarial policy through an asymmetric treatment of individual firms should be 
given a priority. It is noteworthy that the innovation platform, in its beauty contest to select the key innovative sectors in the Netherlands, very much favored those sectors where firms appeared to be able to present themselves jointly in the beauty contest. The implicit intuition of the innovation platform behind this design of the contest may be the desire to enhance future spill-over effects in addition to finding out in which sectors there already were joint $R \& D$ ventures.

\subsection{Corrective Objective versus Strategic Objective}

While the main part of our analysis focuses on the strategic objective of an industrial policy, a policy authority may also have a distortion-corrective objective in mind. In particular, in connection with the $R \& D$ activity by the private firms that are to be influenced by an $R \& D$ policy, the possible sub-optimality of the private firm level investment as raised in the above might induce a government to try to catch both rabbits. Therefore, it has to be understood that the optimal form of the industrial policy - subsidy or tax - depends on which incentive outweighs. From a corrective policy perspective, a tax would have to be imposed if the spillover effect of an R\&D subsidy causes an over-investment for a firm and a subsidy would be optimal if an under-investment is caused. Yet the optimal form of policy from a strategic perspective depends on the other factors such as consumer demand and the completion mode among the firms. If both motives reinforce each other, it is not a concern. However, if the two motives are counteractive, the relative importance of the two objects has to be well weighed before a preferential redesign of the policy is introduced.

\subsection{A Political Economic Concern: Redistribution Scheme}

From the usual perspective of positive economics, when there are winners and losers with the winners' gain bigger than the losers' loss, an appropriate domestic redistribution scheme for a Pareto-efficiency will have to be introduced. A government may want to do this to ensure all participants gain. However, in light of the specific purpose of innovation policy, such as is the objective of e.g. the Dutch innovation platform, one may even leave the outcome as it is. In that way it can be utilized as an incentive scheme for the firms to improve their technology and cost conditions to further guarantee a higher subsidy. In a good scenario, the incentive scheme will lead all the firms in the industry to reach a higher efficiency in absolute terms. If then, the subsidy redesign may rely on the relative measure of efficiency gains to reward only those with high efficiency improvement while those firms with a below-average efficiency gain will still get penalized and receive a lower subsidy. A government may take another stance by rewarding all those with an efficiency gain yet in a discriminatory way. The firms' efforts will be praised 
although unevenly. Of course such non-uniform policy of 'backing strong winners' and 'backing ordinary winners' requires an additional fund for the subsidy spending. The opportunity cost of the public fund will become an issue again, and the government will have to weigh all the related costs and benefits. The costs side would involve both the visible cost and the invisible transaction costs while the benefits should entail the screening effects in this asymmetric information environment to effectively distinguish the low-cost firms from the high-cost firms as well as the usual cost-saving encouraging benefits.

\section{Concluding Remarks}

This paper discusses policy options for industrial and innovation policy using a new feature in strategic trade policy. It illustrates in a theoretical case in an international oligopolistic market under complete information situation that a non-uniform innovation policy through R\&D subsidies is superior to a uniform policy in its domestic welfare enhancing effect. It is shown that the usual retaliation concern that arises from its adverse welfare effects abroad does not apply and that the case holds true under a variety of behavioural conjectures among the firms. The theoretical argument is found useful in the debate on whether a targeted innovation policy is warranted in case the government is to 'pick' or 'back' winners.

Although the benchmark model was sketched in the ideal world with symmetric Cournot firms and it can be extended to the non-Cournot cases as well, asymmetric costs cases in the initial state are more realistic and also the cost-saving effect on the firms or sectors of R\&D subsides will rather be asymmetric. It implies that the government will have to exploit a priori information on the differences of cost reduction that the R\&D subsidy will bring about. That is especially true for the size of the spill-over effects which are positive externalities and may lead to under-investment in $R \& D$ unless it is internalized within the system or through an industrial policy. The problem is that the government has incomplete information on the true initial efficiency levels of the firms and on the extent of cost reduction that the subsidy will bring about. Firms may be induced to behave strategically to persuade the government through an information revelation, which could even lead to over-investment and to rent seeking. It requires the government to design a carefully deliberated strategy for innovation policy and must at least be consistent in keeping that strategy. Nonetheless, the rationale of the aggregate profit creation remains valid as long as the policy maker can sort out the informational asymmetry to clearly configure the initially optimal policy form. Furthermore, it may bring about the additional benefit of inducing extra efforts on the firms' side. 
From this perspective, our analysis discusses the various strategic issues for a targeted innovation policy with their pros and cons. It takes as example the strategy of the Dutch innovation platform, which designed a beauty contest in order to select key innovative sectors in the Netherlands following the policy proposals to conduct a policy of 'backing winners'. Informational configuration about the current efficiency conditions of the market participants has to be preceded and also the potential efficiency-gains through the policy has to be well estimated, while the potential opportunistic behavior by the firms should be discouraged. A carefully designed mechanism to provide the firms the right incentives and also to monitor their post-policy behavior should be combined as well. In addition, the 'challengers' should not be completely isolated from the whole picture and the strategic details of the policy should entail backing the right winners - both existing and potential.

As a final remark, we note that the analysis of this paper does, by no means, rule out the possibility that the ex-ante optimal form of the policy may be indeterminate or that the informational complexity may lead to a substantial transaction cost loss so that eventually it has negative welfare implications. The discussion of the policy options in this paper only has a qualitative character and is based on modern theory of strategic firm behavior. A more fully fledged analysis would need a formal treatment of the specific strategies. Then a quantification of the net welfare effects that the optimal design of the policy strategies can bring about, is to be made. These net welfare effects may turn out to be positive, but can also very well appear to be negative. In other words, in spite of the theoretical model of this paper, which provides an argument for backing winners, in practice the cons of such policy may outweigh the pros. This is the scope for future research. 


\section{Appendix}

1. Proof of aggregate profit creation when the subsidies are rearranged only at two firms:

(i) Homogeneous cost

Consider the case where the initially-uniform subsidies are rearranged only at two of the $n$ initially identical domestic firms, which we denote by firm 1 and firm 2. Initially $s_{1}=s_{2}, k_{1}=k_{2}$ and $x_{1}=x_{2}$. Assume the subsidy is reduced on firm 1 and raised on firm 2, preserving their sum. Then $\Delta k_{1}>0, \Delta k_{2}<0, \Delta k_{1}+\Delta k_{2}=0$ and it follows from Proposition 4 and Lemma 3 that $\Delta x_{1}<0, \Delta x_{2}>0$ and $\Delta x_{1}+\Delta x_{2}=0$. Given this, we explore the change in aggregate production cost for the domestic firms given by the following:

$$
\begin{aligned}
& \left(\left(k_{1}+\Delta k_{1}\right)\left(x_{1}+\Delta x_{1}\right)-k_{1} x_{1}\right)+\left(\left(k_{2}+\Delta k_{2}\right)\left(x_{2}+\Delta x_{2}\right)-k_{2} x_{2}\right) \\
& =\left(\Delta k_{1} \Delta x_{1}+\Delta k_{2} \Delta x_{2}\right)+\left(k_{1} \Delta x_{1}+k_{2} \Delta x_{2}\right)+\left(x_{1} \Delta k_{1}+x_{2} \Delta k_{2}\right)
\end{aligned}
$$

In the above, the second and the third term is equal to zero because $k_{1}=k_{2}, \Delta x_{1}+\Delta x_{2}=$ 0 and $x_{1}=x_{2}, \Delta k_{1}+\Delta k_{2}=0$, respectively. And the first term $\left(\Delta k_{1} \Delta x_{1}+\Delta k_{2} \Delta x_{2}\right)$ will be strictly negative since $\Delta x_{i}$ and $\Delta k_{i}$ take the opposite sign from each other. Therefore, the change in aggregate cost in (A1) is strictly negative.

\section{(ii) Heterogeneous Cost}

Now suppose the firms costs were asymmetric initially for two firms; $c_{1}>c_{2}$ and $s_{1}<s_{2}$ initially, and subsidies are redesigned only on these two firms in such way that $\Delta s_{1}<0, \Delta s_{2}>0$ and $\Delta s_{1}+\Delta s_{2}=0$. Then, it follows that $\Delta k_{1}>0, \Delta k_{2}<0$ and $\Delta k_{1}+\Delta k_{2}=0$ and Proposition 4 implies that $\Delta x_{1}<0, \Delta x_{2}>0$ and $\Delta x_{1}+\Delta x_{2}=0$. Therefore $k_{1}>k_{2}$ and $x_{1}<x_{2}$. From (17), the aggregate production cost is

$$
\left(\Delta k_{1} \Delta x_{1}+\Delta k_{2} \Delta x_{2}\right)+\left(k_{1} \Delta x_{1}+k_{2} \Delta x_{2}\right)+\left(x_{1} \Delta k_{1}+x_{2} \Delta k_{2}\right) .
$$

The first term in (24) remains strictly negative. The second term is also strictly negative since $k_{1} \Delta x_{1}<0, k_{2} \Delta x_{2}>0$ and $\left|k_{1} \Delta x_{1}\right|>\left|k_{2} \Delta x_{2}\right|$, and the third term is also strictly negative since $x_{1} \Delta k_{1}>0, x_{2} \Delta k_{2}<0$ and $\left|x_{1} \Delta k_{1}\right|<\left|x_{2} \Delta k_{2}\right|$. Hence the aggregate production cost decreases and the aggregate profit increases. One implication from this subsection is that a country should help those firms which are already cost-competitive, which contrasts with the conventional infant industry argument. 


\section{References}

AWT: Advisory Council for Science and Technology Policy (2003), Backing Winners; van generiek technologiebeleid naar actief innovatiebeleid, Report 53, July 2003.(in Dutch).

Bergstrom, T. C. and Varian H. R. (1985), Two Remarks on Cournot Equilibrium", Economic Letters, 19, pp.5-8.

Bowley, A. (1924), Mathematic Foundations of Economics. New York, Oxford University Press.

Brander, J. A. (1995), Strategic Trade Policy, in Grossman G. and K. Rogoff, eds., Handbook of International Economics, Vol. III (Elsevier Science B. V., Netherlands).

Brander, J. A. and B. J. Spencer (1985), Export Subsidies and Market Share Rivalry, Journal of International Economics, 18, pp. 83-100.

Eaton, J. and Grossman G. M. (1986), Optimal Trade and Industrial Policy under Oligopoly. Quarterly Journal of Economics, 101, pp. 383-406.

Gruenspecht, H. K. (1988), Export Subsidies for Differentiated Products, Journal of International Economics, 24, 331-344.

Jacobs, B. and J. Theeuwes (2005), Innovation in The Netherlands: the market falters and the government fails, De Economist, 153, pp. 107-124.

Jo, S-G. (2008), Non-uniform Strategic Trade Policy and Aggregate Profit Creation, under review, Scottish Journal of Political Economy.

Jo, S-G. (2009), Similarity and Dissimilarity between Export Subsidies and R\&D Subsidies. mimeo, Amsterdam: Vrije Universiteit Amsterdam.

Kujal, P. and Ruiz J. M. (2007), Cost Effectiveness of R\&D and Strategic Trade Policy. The B.E. Journal of Economic Analysis \& Policy, 7, issue 1, Article 21.

Leahy, D. and Montagna C. (1998). Targeted Strategic Trade Policy with Domestic Cost Heterogeneity. Dundee Discussion Papers in Economics, Dundee, UK: University of Dundee

Maggi, G. (1999), Strategic Trade Policy under Incomplete Information. International Economic Review, 40, pp. 571-594.

Neary, J. P. (2000), R\&D in Developing Countries: What Should Governments Do? London: Center for Economic Performance, London School of Economics and Political Sciences.

Neary, J. P. and O'Sullivan, P. (1999), Beat'em or Join'em? Export Subsides versus International Research Joint Ventures in Oligopolistic Markets, Scandinavian Journal of Economics, 101, pp. 577-596.

Neary, J. P. (1994), Cost Asymmetries in International Subsidy Games: Should Government Help Winners or Losers? Journal of International Economics, 37, pp. 197-218.

Qiu, L. D. (1994), Optimal Strategic Trade Policy under Asymmetric Information. Journal of International Economics, 36, pp. 333-354.

Salant, S.W. and Shaffer G. (1999), Unequal Treatment of Identical Agents in Cournot Equilibrium. American Economic Review, 89, pp.585-604.

Supasri, Y. and Tawada M. (2007), Endogenous Timing in a Strategic Trade Policy Game: A TwoCountry Oligopoly Model with Multiple Firms. Review of Development Economics, 11, pp. 275-290.

WRR: Scientific Council for Government Policy (2008), Innovatie vernieuwd: opening in viervoud, Reports to the Government nr. 80, Amsterdam University Press, Amsterdam (in Dutch). 